\title{
Longitudinal analysis of gamma delta T cell subsets during malaria infections in Malian adults
}

\author{
Hama Diallo', Abdoulaye Katile', Jennifer L. Kwan², Mahamadou S. Sissoko', Sara A. Healy², \\ Ogobara K. Doumbo ${ }^{1}$, Patrick E. Duffy ${ }^{2^{*}}$ (1) and Irfan Zaidi ${ }^{2}$
}

\begin{abstract}
Background: Immunity that limits malarial disease is acquired over time, but adults living in endemic areas continue to become infected and can require treatment for clinical illness. Gamma delta $(\gamma \delta) T$ cells, particularly the V $\delta 2+$ subset, have been associated with development of clinical malaria in children. In this study, the dynamics of total $ү \delta \mathrm{T}$ cells, V82+ and V $82-T$ cells were measured during a malaria transmission season in Malian adults.

Methods: This study explored $\gamma \delta T$ cell dynamics and Plasmodium falciparum infection outcomes over the course of the malaria transmission season in Malian adults enrolled in the placebo arm of a double-blind randomized vaccine trial. All volunteers were treated with anti-malarial drugs prior to the start of the transmission season and blood smears were assessed for P. falciparum infection every 2 weeks from July 2014 to January 2015. The study participants were stratified as either asymptomatic infections or clinical malaria cases. $V \delta 2+$ and $V \delta 2-\gamma \delta T$ cell frequencies and activation (as measured by CD38 expression) were measured in all study participants at baseline and then every 2 months using a whole blood flow cytometry assay.
\end{abstract}

Results: Forty of the forty-three subjects became infected with P. falciparum and, of those, 21 individuals were diagnosed with clinical malaria at least once during the season. The $\gamma \delta T$ cell percentage and activation increased over the duration of the transmission season. Both the $V \delta 2+$ and $V \delta 2-\gamma \delta T$ cells were activated by $P$. falciparum infection.

Conclusion: $\gamma \delta T$ cells increased during a malaria transmission season and this expansion was noted in both the $V \delta 2+$ and $V \delta 2-\gamma \delta T$ cells. However, neither expansion or activation of either $\gamma \delta T$ cell subsets discriminated study participants that had asymptomatic infections from those that had clinical malaria cases.

Keywords: Clinical malaria, Plasmodium falciparum, $ү \delta T$ cells, Longitudinal analysis

\section{Background}

Malaria remains an acute public health problem with 216 million reported cases that led to 445,000 deaths in 2016. Sub-Saharan Africa continues to be the most affected region and accounted for $91 \%$ of malaria cases and $90 \%$ of malaria deaths in 2016 [1]. The most severe form of malaria is caused by Plasmodium falciparum and

\footnotetext{
*Correspondence: patrick.duffy@nih.gov

${ }^{2}$ Laboratory for Malaria Immunology and Vaccinology, National Institute of Allergy and Infectious Diseases, National Institutes of Health, Rockville, MD, USA

Full list of author information is available at the end of the article
}

accounts for the majority of deaths, especially in children under the age of 5 years.

Despite repeated infections, sterile immunity to $P$. falciparum infection is not thought to develop $[2,3]$. However, there is evidence for clinical immunity against malaria as evidenced by reduced clinical cases and greater proportions of asymptomatic infections in older children and adults [4]. Development of clinical immunity has been associated with blunted Th1 immune responses, and increases in immunoregulatory mechanism, such as $\mathrm{T}$ regulatory cells and IL-10 production from CD4 $\mathrm{T}$ cells [5-7]. More recently, reduced responses of gamma delta $(\gamma \delta)$ T cell responses to P. falciparum infections 
were associated with development of clinical immunity and this was attributed to the $\mathrm{V} \delta 2 \gamma \delta \mathrm{T}$ cell subset in particular [8]. $\gamma \delta^{+}$T lymphocytes have been reported to be elevated in peripheral blood [9] and spleens of individuals with acute or convalescent $P$. falciparum infection [10]. The high level of these cells has also been observed during febrile paroxysms of Plasmodium vivax infection [11]. Proportional expansion of both $V \delta 1^{+}$and $V \delta 2^{+}$ subsets has been reported in acute $P$. falciparum infection $[12,13]$.

$\gamma \delta \mathrm{T}$ cells are a specialized subset that have features of both innate and adaptive immune cells [14]. Their T cell receptor consists of a gamma and a delta chain and are usually identified according to the delta chain expressed on the surface. Hence, $\gamma \delta \mathrm{T}$ cells are classified as V $\delta 1+$, $\mathrm{V} \delta 2+$ and a minor subset, $\mathrm{V} \delta 3+$. The $\mathrm{V} \delta 2+\gamma \delta \mathrm{T}$ cells are typically the predominant circulating subset in the blood and their TCR consists of a V $\delta 2$ and a $V \gamma 9$ chain [15]. The V $\delta 1+\mathrm{T}$ cell subset can constitute the major subset of $\gamma \delta \mathrm{T}$ cells but they have a wider gamma chain usage including $V \gamma 9$ [16].

The PfSPZ vaccine trial in Mali evaluated the efficacy of the Sanaria ${ }^{\circledR}$ whole sporozoite vaccine to $P$. falciparum infection in the field and required very intense follow-up of study participants [17]. Using a treatment-reinfection approach, the clinical outcomes of $P$. falciparum infection were evaluated in the study participants. Furthermore, whether the dynamics of $\gamma \delta$ T cells would distinguish asymptomatic infections and clinical malaria cases was evaluated. In over half of the adults in the study, $P$. falciparum infections resulted in clinical malaria cases, but neither the percentage nor activation of $\gamma \delta \mathrm{T}$ cells discriminated clinical malaria cases from asymptomatic infections.

\section{Methods}

\section{Human ethics statement}

All subjects provided written informed consent before screening. Ethics Committee (EC) of Faculté de Médecine de Pharmacie et d'OdontoStomatologie (FMPOS) and the NIAID Institutional Review Board (IRB) approved the study protocol (Number: 14-I-N010).

\section{Study design}

The data from this study were from the placebo group in the recently concluded PfSPZ Vaccine trial. This study was conducted in Mali through the Malaria Research Training Center (MRTC) of the Medical School of the University of Sciences, Techniques and Technologies of
Bamako (USTTB) from August 2014 to January 2015. The study was conducted according to Good Clinical Practices including external monitoring of the data.

\section{Study participants}

Forty-four of the 48 subjects that were enrolled in the placebo group completed the study and these were used for this analysis. The volunteers were healthy adults between 18 and 35 years old and were screened for eligibility based on residency in the village, their medical and family history, as well as their physical examination. None of the female volunteers were pregnant or lactating. Serology for HIV, hepatitis B and C was negative for all volunteers before inclusion. All volunteers provided written informed consent before screening.

\section{Study procedures}

Study participants were assayed at the start of the transmission season (day/week 0), 6 weeks (day 38) and 14 weeks (day 98) later, and at the end of the study at 22 weeks (day 154) as malaria transmission waned. At each visit, $1 \mathrm{ml}$ of whole blood was drawn for parasite detection by thick smear and immunological ex vivo assays. Volunteers were treated with artemether/lumefantrine approximately 4 weeks before the day 0 visit. Participants were encouraged to make unscheduled visits anytime during the study period if they experienced any clinical symptoms.

\section{Peripheral blood smears}

Thick blood smears were prepared from finger prick samples starting at day 0 and then every 2 weeks until the end of the study. Certified technicians examined the smears following established procedures for malaria slide reading within the MRTC, Mali. Blood films were considered positive if at least two unambiguous Plasmodium parasites were seen.

\section{Clinical malaria and asymptomatic infection case definitions}

In accordance with Malian national treatment guidelines, symptomatic malaria was defined as $P$. falciparum asexual parasitaemia accompanied by an axillary temperature of at least $37.5^{\circ} \mathrm{C}$ and/or clinical signs and symptoms compatible with malaria. If a subject was diagnosed with symptomatic malaria, subjects were treated with artemether-lumefantrine. 
Clinical malaria cases were defined as having an axillary temperature of $37.5{ }^{\circ} \mathrm{C}$, clinical signs and symptoms of malaria. All per protocol (scheduled) anti-malarial treatments were administered by directly observed treatment by study staff. Participants were instructed that if they vomited within $1 \mathrm{~h}$ of taking the drug, they should return to the clinical trial centre to receive a repeat dose. Asymptomatic $P$. falciparum infection cases were not treated, as per national malaria guidelines.

\section{Immunological analysis}

One $\mathrm{ml}$ of whole blood was collected in a sodium heparin tube from each volunteer at study day 0 , day 38 , day 98 and day 154 during the period of the study, which coincided with a clinical follow-up visit day. One hundred fifty $\mu \mathrm{l}$ of whole blood was used for staining with a cocktail of antibodies against: anti-CD3 BV650, antiCD8 APC-H7, anti- $\gamma \delta$ TCR PE, anti-V $\delta 2$ FITC purchased from e-bioscience. Red blood cells were lysed using the BD FACS Lyse solution and the cells were washed two times with PBS and acquired on a LSRII flow cytometer equipped with a Blue $(488 \mathrm{~nm})$, Red $(633 \mathrm{~nm})$ and Violet laser $(405 \mathrm{~nm}) \cdot \gamma \delta \mathrm{T}$ cells (V $\delta 2+$ and $\mathrm{V} \delta 2-$ populations) were enumerated as a percentage of total CD3 $\mathrm{T}$ cells.

\section{RNA sequencing}

Whole blood was collected in PAXgene tubes from study subjects at the begininning of the transmission season (Day 0). The methods used for RNA isolation, sequencing and subsequent bioinformatics analysis are previously described [18]. The raw data was processed as previously described and the Reads Per Kilobase of transcript per Million mapped reads (RPKM) were generated for all genes. Only $\mathrm{T}$ cell receptor gamma and delta genes were selected for further analysis. The relative expression (as assessed by mean RPKM values) of $\mathrm{T}$ cell receptor $\mathrm{V}$ delta (TRDV1, TRDV2 and TRDV3) and gamma genes (TRGV1, TRGV2, TRGV3, TRGV5, TRGV5P, TRGV6, TRGV7, TRGV8, TRGV9, TRGV10 and TRGV11) were compared.

\section{Statistical analyses}

Statistical analyses were performed using Prism7 (Graph $\mathrm{Pad}$ ). The associations between immunologic outcomes with exposure variables were examined, including prior cumulative incidence, concurrent parasitemia at the time of the assay, and anti-malarial treatment allocation. The comparisons of cellular percentages were performed using the nonparametric Kruskal-Wallis to compare all the groups and Mann-Whitney test to compare between the groups. A p value of $<0.05$ was considered statistically significant.

\section{Results \\ Plassmodium falciparum infections}

Malaria transmission in Mali is highly seasonal and closely aligned to the rainy season that begins in July and concludes in December. The study was conducted in Donéguébougou, Mali which is $30 \mathrm{~km}$ from the capital Bamako. Forty-four subjects that were enrolled in the placebo arm of the PfSPZ Vaccine trial in Mali were used for the analysis of $\gamma \delta \mathrm{T}$ cells across the malaria transmission season in 2014.

The volunteers had a median age of 24 years (range $18-35)$ and were predominantly male (41/44). A total of 119 positive blood smears were recorded in the 41 participants. Consecutive positive blood smears recorded within 28 days in individual subjects were counted as a single infection. Three study volunteers remained uninfected throughout the study period, as assessed by blood smear results, and were excluded from further analysis. Additional details of study participants were reported in the publication describing the PfSPZ Vaccine trial results in Mali [17]. The frequency of positive blood smears was highest during weeks $8-12$, with 15 recorded infections, and transmission continued till the end of the follow-up period at week 22. Study participants were classified as either clinical malaria or asymptomatic infection groups. Any volunteer who was treated for symptomatic malaria anytime during the season was included in the clinical malaria group. Volunteers who had a positive blood smear but had no symptoms were included in the asymptomatic infection group. A total of 28 clinical malaria cases were recorded in 21 unique individuals during the transmission season. Clinical malaria cases peaked between weeks 10 and 12 (Fig. 1a, b).

The time to first infection between the clinical and asymptomatic groups was analyzed and median time to first infection was not significantly different between the two groups (61.5 versus 50 days, $\mathrm{p}=0.1238$, Log-Rank test, Fig. 2).

\section{$\gamma \delta \mathrm{T}$ cell frequencies}

During the course of the study, whole blood was used to enumerate total $\gamma \delta$ T cells and the $V \delta 2+\gamma \delta \mathrm{T}$ cell subset. The gating strategy is shown in Fig. 3. At least two distinct populations of $\gamma \delta$ T cells were visible and the V $\delta 2+$ subset was distinguished by lower expression levels of $\gamma \delta$ TCR as previously shown [18]. CD45RO expression was 

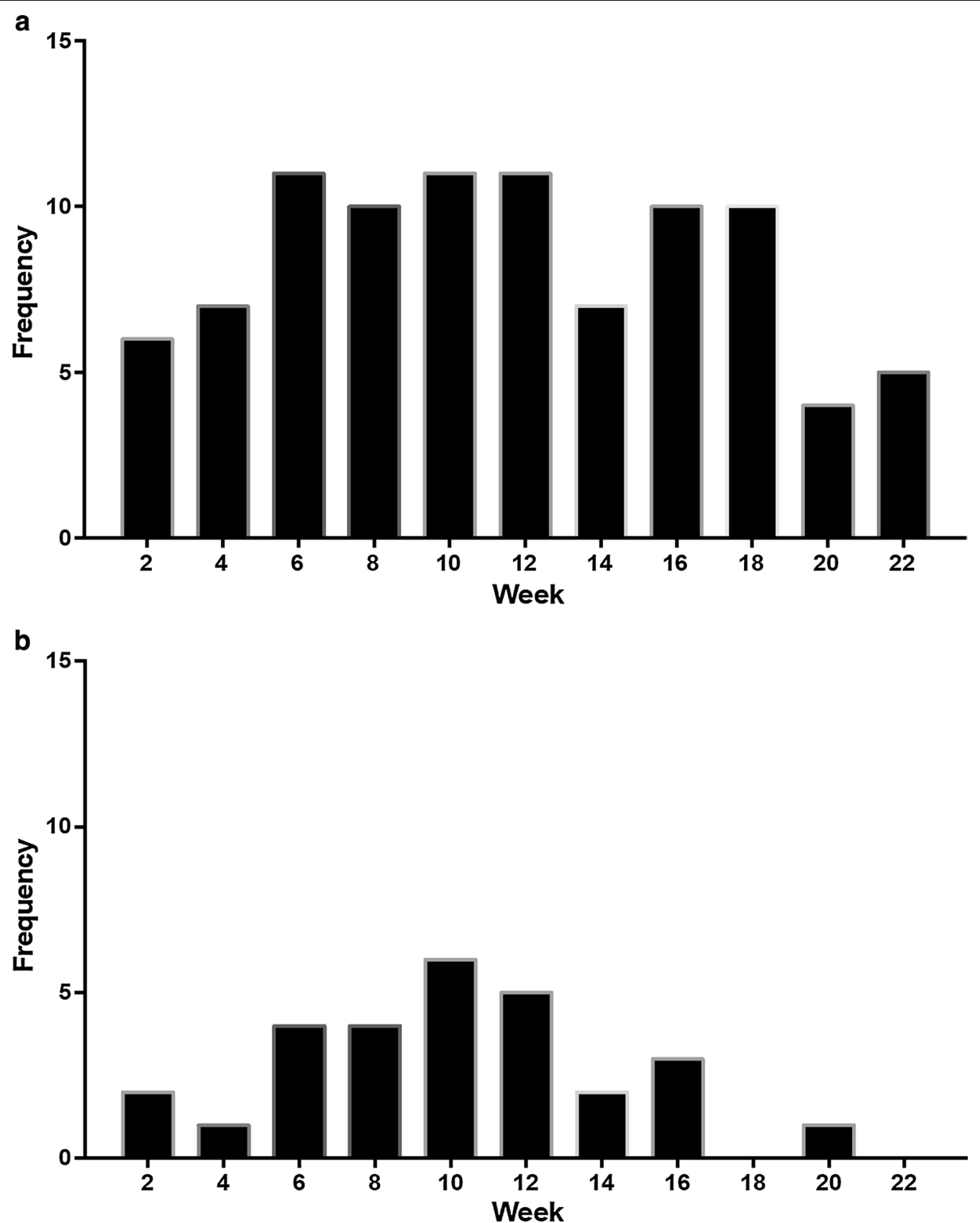

Fig. 1 Frequency of Plasmodium falciparum infections. a Number of positive blood smears recorded bi-weekly. b Number of clinical malaria cases recorded bi-weekly 


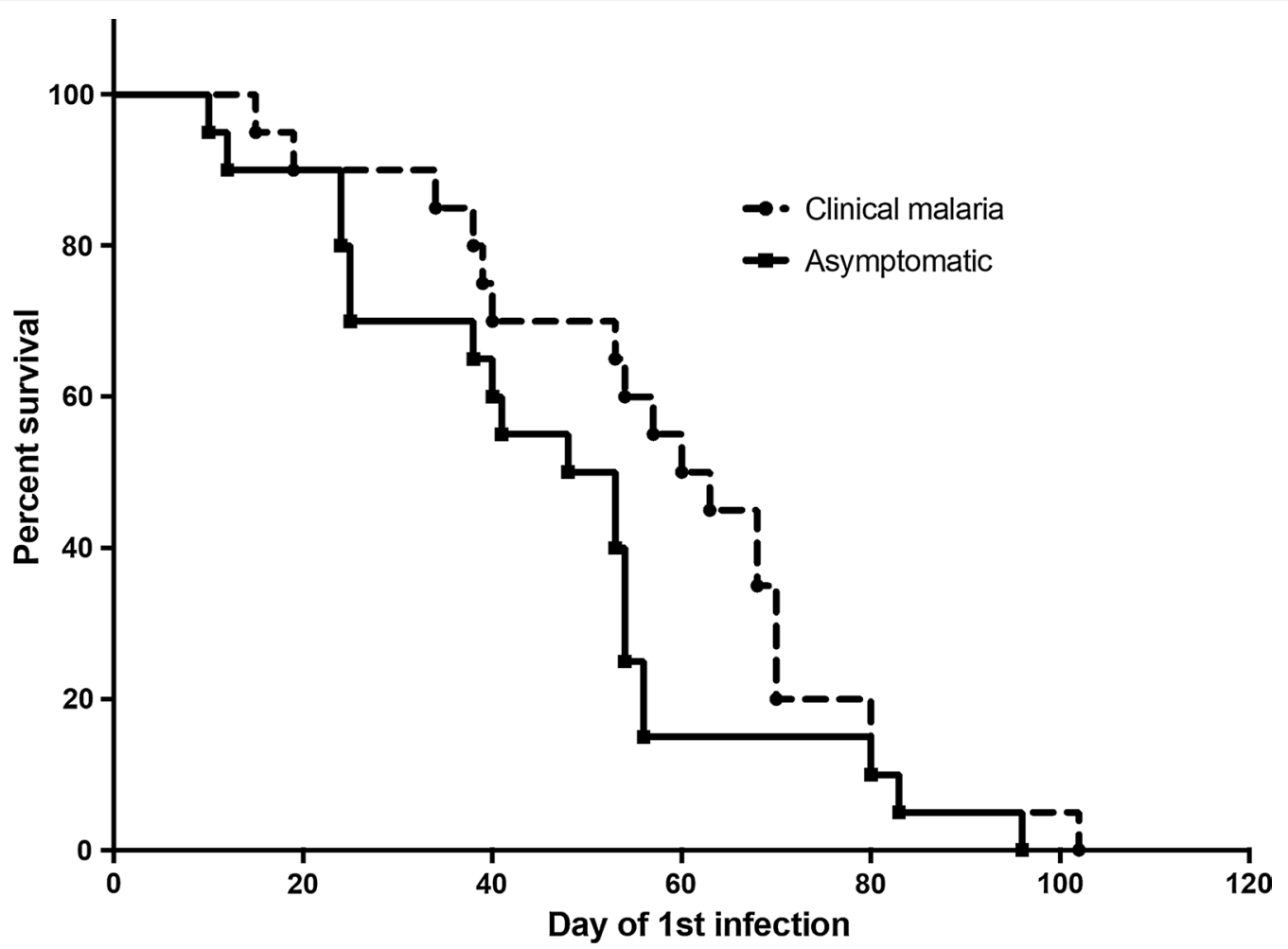

Fig. 2 Time to first infection between clinical cases and asymptomatic infections

only seen on the $\mathrm{V} \delta 2+$ subset while a significant proportion of $V \delta 2-\gamma \delta$ T cells also expressed CD8 $\alpha$.

\section{$V$ gamma and delta chain usage}

RNA from 6 subjects used in this analysis were previously used for sequencing and the results were submitted to a publically available repository [18]; (Accession number: GSE86308). The data were used to infer the relative abundance of $\gamma \delta$ T cell subsets. Two subjects were in the clinical malaria group and 4 in the asymptomatically infected group. Comparison of the RPKM values of the TRVD genes showed that overall the expression of TRDV1 was highest followed by TRDV2 and lastly TRDV3 (Fig. 4a). A similar analysis was done for the TRGV genes. TRGV9 had the highest RPKM values followed by TRGV10 (Fig. 4b).

\section{Comparison of $\gamma \delta \mathrm{T}$ cell frequencies}

The levels of total $\gamma \delta \mathrm{T}$ cells, V $\delta 2+$ and $\mathrm{V} \delta 2$ - subsets were compared between clinical malaria cases and asymptomatic infections at the start of the transmission season (day 0), 6 weeks (day 38), 14 weeks (day 98) and at the end of the study at 22 weeks (day 154). The ratio of $\mathrm{V} \delta 2+$ to $V \delta 2-\gamma \delta \mathrm{T}$ cells was similar at all time points between volunteers who had asymptomatic or clinical malaria cases (Fig. 5a). Comparison of the total percentage of $\gamma \delta \mathrm{T}$ cell in all study subjects showed an increase from baseline and peaked at day 98 in all study subjects but the differences were not statistically significant at any time point. Comparison of the V $\delta 2-$ and V $\delta 2+$ subsets dynamics did not discriminate individuals who developed clinical malaria versus only asymptomatic infections during the season (Fig. 5c, d). 


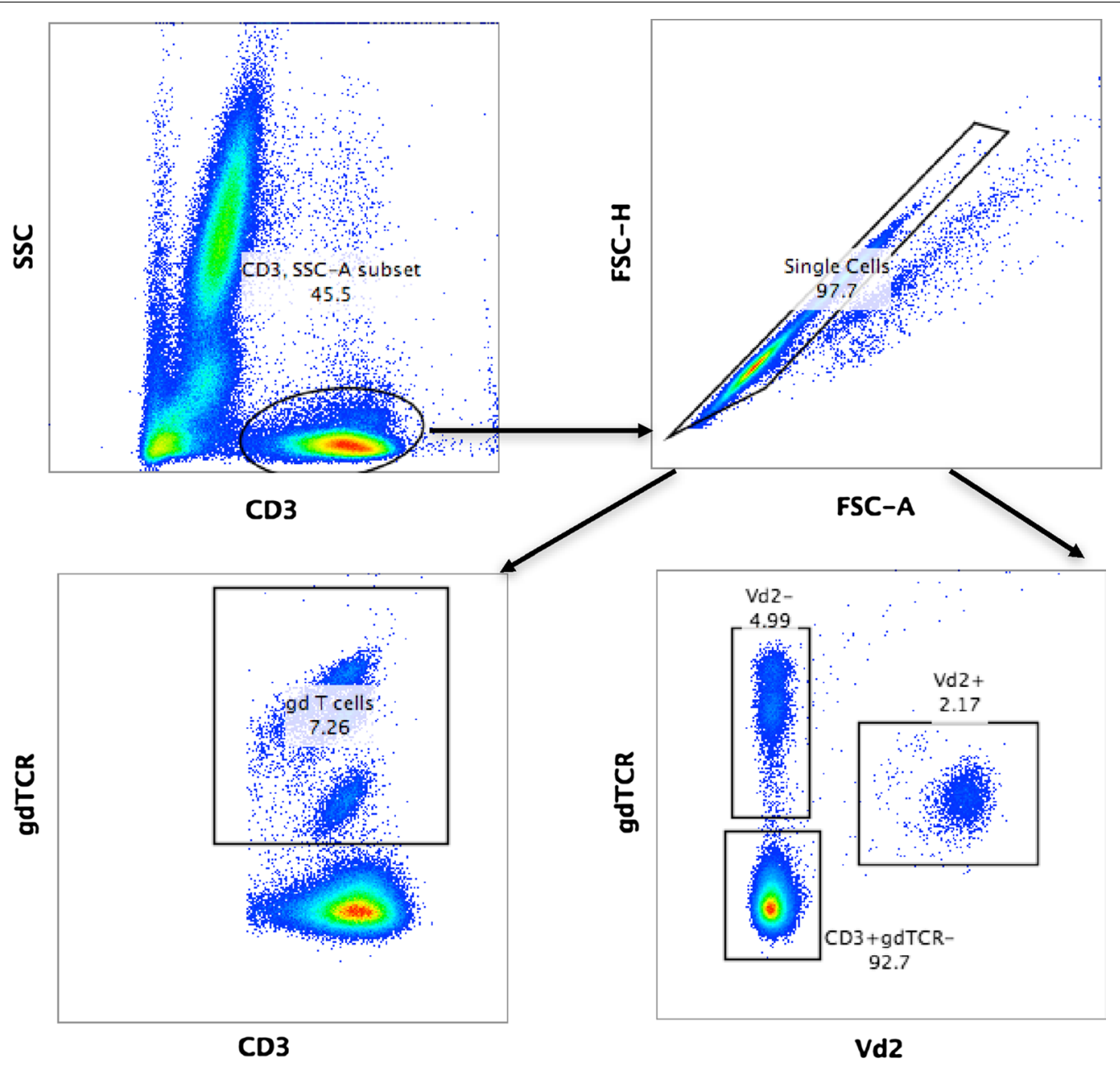

Fig. 3 Flow cytometry gating strategy. Total CD3 + events were gated and then doublets were excluded. Total $\gamma \delta T C R+T$ cells, V $\delta 2+$ and V $\delta 2-$ $\gamma \delta T C R+T$ cells were then enumerated as a percentage of CD3+ events

\section{$\gamma \delta \mathrm{T}$ cell activation}

Activation of $\gamma \delta \mathrm{T}$ cells was assessed by measuring CD38 co-expression (Fig. 6a). The percent of $\gamma \delta \mathrm{TCR}+\mathrm{CD} 38+$ from all subjects increased from baseline to the end of the study at D154 (Fig. 6a, p=0.01, paired $\mathrm{t}$ test). The next analysis evaluated the activation levels within the $\mathrm{V} \delta 2-$ and $\mathrm{V} \delta 2+\gamma \delta \mathrm{T}$ cells respectively. The percentage of $\mathrm{V} \delta 2-\mathrm{CD} 38+$ and $\mathrm{V} \delta 2+\mathrm{CD} 38+\gamma \delta \mathrm{T}$ cells was significantly higher at day 154 than at baseline (Fig. 6c, p $=0.037$ and Fig. 6d, $p=0.0036$, respectively, paired $t$ test). The percentages of total $\gamma \delta \mathrm{T}$ cells that were $\mathrm{CD} 38+, \mathrm{V} \delta 2-\mathrm{CD} 38+$ or $\mathrm{V} \delta 2+\mathrm{CD} 38+$ were not significantly different between the clinical malaria and asymptomatically infected groups.

\section{Discussion}

In the current study, malaria infections were monitored in Malian adults who were enrolled in the placebo arm of a recently concluded vaccine trial [17] and compared the levels, activation and subsets of $\gamma \delta \mathrm{T}$ cell prior to and during the transmission season. This study followed a treatment-reinfection design and this allowed us to 

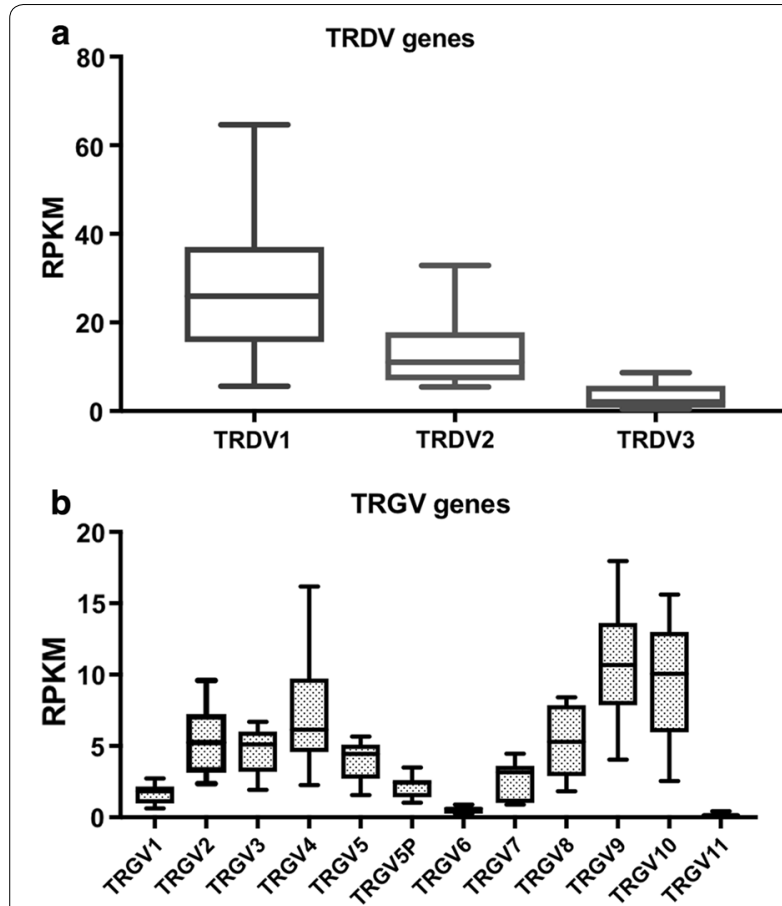

Fig. $4 \mathrm{~V}$ delta and gamma gene expression. Transcriptomic analysis of RPKM of $\mathbf{a} \vee$ delta genes, $\mathbf{b} \vee$ gamma genes in 6 study volunteers

monitor the clinical outcome of infection and relate this to changes in $\gamma \delta$ T cell dynamics. Almost all (41/44, 93\%) of participants were infected at least once, confirming the absence of sterilizing immunity as has been previously documented in semi-immune populations [3]. However, infection outcomes differed where half the participants developed clinical malaria at least once and required treatment, whereas others only experienced asymptomatic infection and displayed no signs of disease. There was no significant difference in the time to first infection between the clinical malaria and asymptomatic infections, suggesting that immune factors are contributing to the differential outcome instead of differences in infecting $P$. falciparum parasites.

Recent studies have highlighted a potential role for $\gamma \delta$ $\mathrm{T}$ cells in malaria disease pathogenesis $[8,19]$. During this study $\gamma \delta \mathrm{T}$ cells in adults were measured to evaluate whether the phenotype, frequency and activation were altered during the malaria transmission season and whether they associated with risk of malarial disease. The profile of $\gamma \delta \mathrm{T}$ cells was dominated by V $\delta 2-$ $\gamma \delta \mathrm{T}$ cells, which were higher than $\mathrm{V} \delta 2+\gamma \delta \mathrm{T}$ cells in the majority of the volunteers in this study. This is in stark contrast to populations living in developed countries, where the predominant circulating $\gamma \delta \mathrm{T}$ cell subsets are the $\mathrm{V} \delta 2+\mathrm{T}$ cells [15]. Previous studies [20, 21] have demonstrated that adults living in malaria endemic regions have greater proportions of $\mathrm{V} \delta 1+\gamma \delta$ $\mathrm{T}$ cells in the periphery when compared to malaria naïve individuals. While we did not stain for $\mathrm{V} \delta 1+\gamma \delta$ $\mathrm{T}$ cells, the transcriptomics analysis performed from a subset of volunteers in this study clearly demonstrated that the expression profile of the $\mathrm{V}$ delta genes was dominated by TRDV1 gene, which codes for the $\mathrm{V}$ delta 1 chain. This may have important implications for malaria vaccines (especially whole organism vaccines). It has been shown that V $\delta 2+$, but not V $\delta 1, \gamma \delta$ $T$ cells are expanded after administration of the whole organism PfSPZ Vaccine in Malian adults [18]. While it is clear that $\mathrm{V} \delta 2+\gamma \delta \mathrm{T}$ cells respond to metabolites of the Plasmodium DOXP pathway [22], it remains unclear how $\mathrm{V} \delta 1+\mathrm{T}$ cells are activated by P. falciparum infections and this requires further exploration. Furthermore, determining whether the difference in $\gamma \delta \mathrm{T}$ cell profiles between malaria naïve and malaria exposed populations is due to host genetics or pathogen exposure warrants closer examination.

Recent studies have highlighted the role of $\gamma \delta \mathrm{T}$ cell levels in the pathogenesis of malaria in children $[8,19,23]$. These studies collectively suggest that $\mathrm{V} \delta 2+\mathrm{T}$ cell activation is associated with onset of clinical malaria and their responses are quickly blunted as a result of increased expression of inhibitory molecules such as TIM-3 [24]. In this study, the percentage of $V \delta 2+\gamma \delta \mathrm{T}$ cells did not distinguish adults that developed clinical disease or had only asymptomatic infections. It is tempting to speculate that these differences maybe due to altered responses to Plasmodium antigens, expression of inhibitory molecules as well as differentiation status of $V \delta 2 \gamma \delta \mathrm{T}$ cells in adults and infants. 


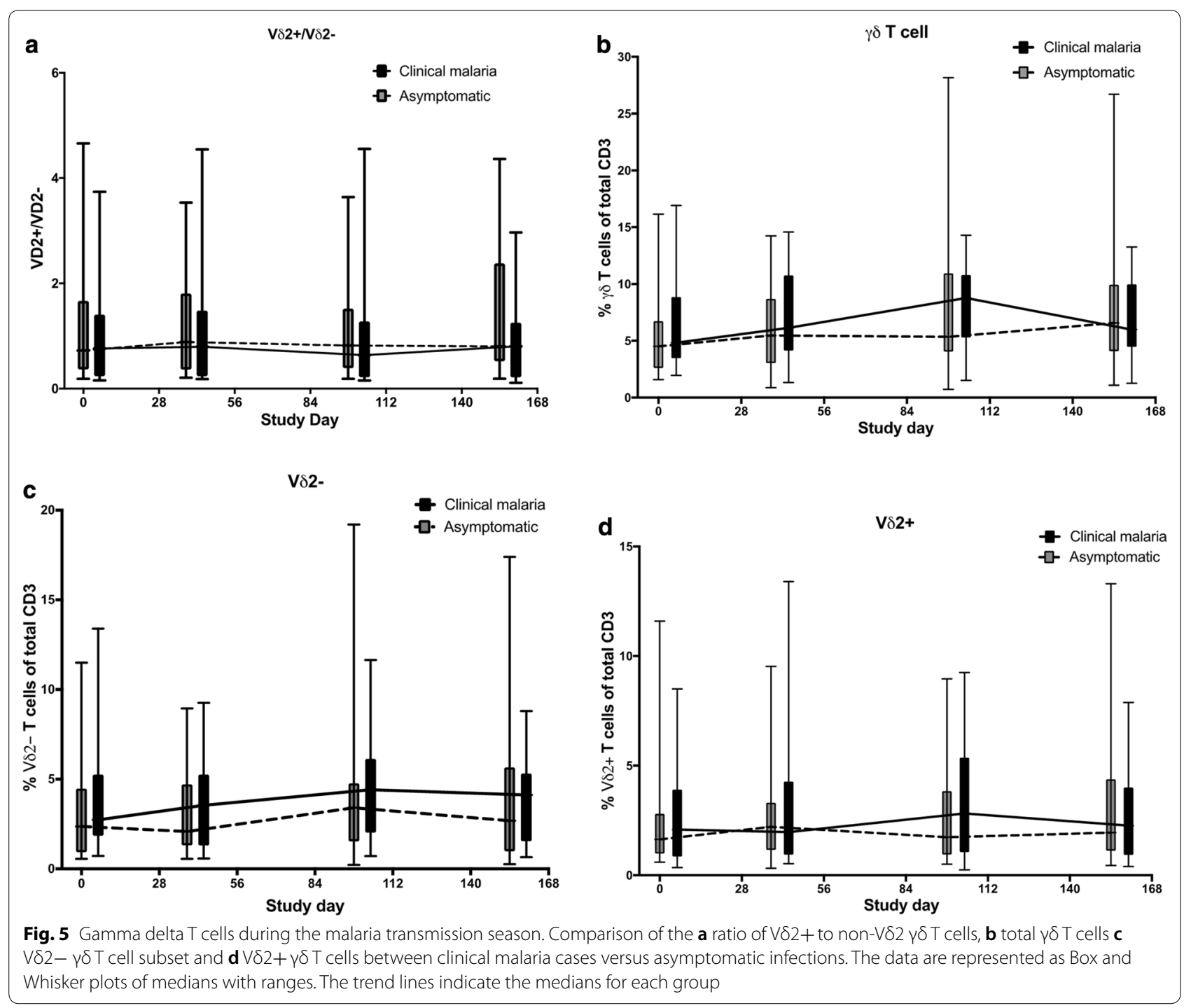

\section{Conclusions}

In summary, the results of this study show that semiimmune adults living in an areas of seasonal malaria transmission continue to experience clinical malaria episodes and the heterogeneity in clinical outcomes of $P$. falciparum infections were not dictated by their $\gamma \delta$ T cell profiles.

$\gamma \delta \mathrm{T}$ cells increased during a malaria transmission season and this expansion was noted in both the $\mathrm{V} \delta 2+$ and $\mathrm{V} \delta 2-\gamma \delta \mathrm{T}$ cells. However, neither expansion or 


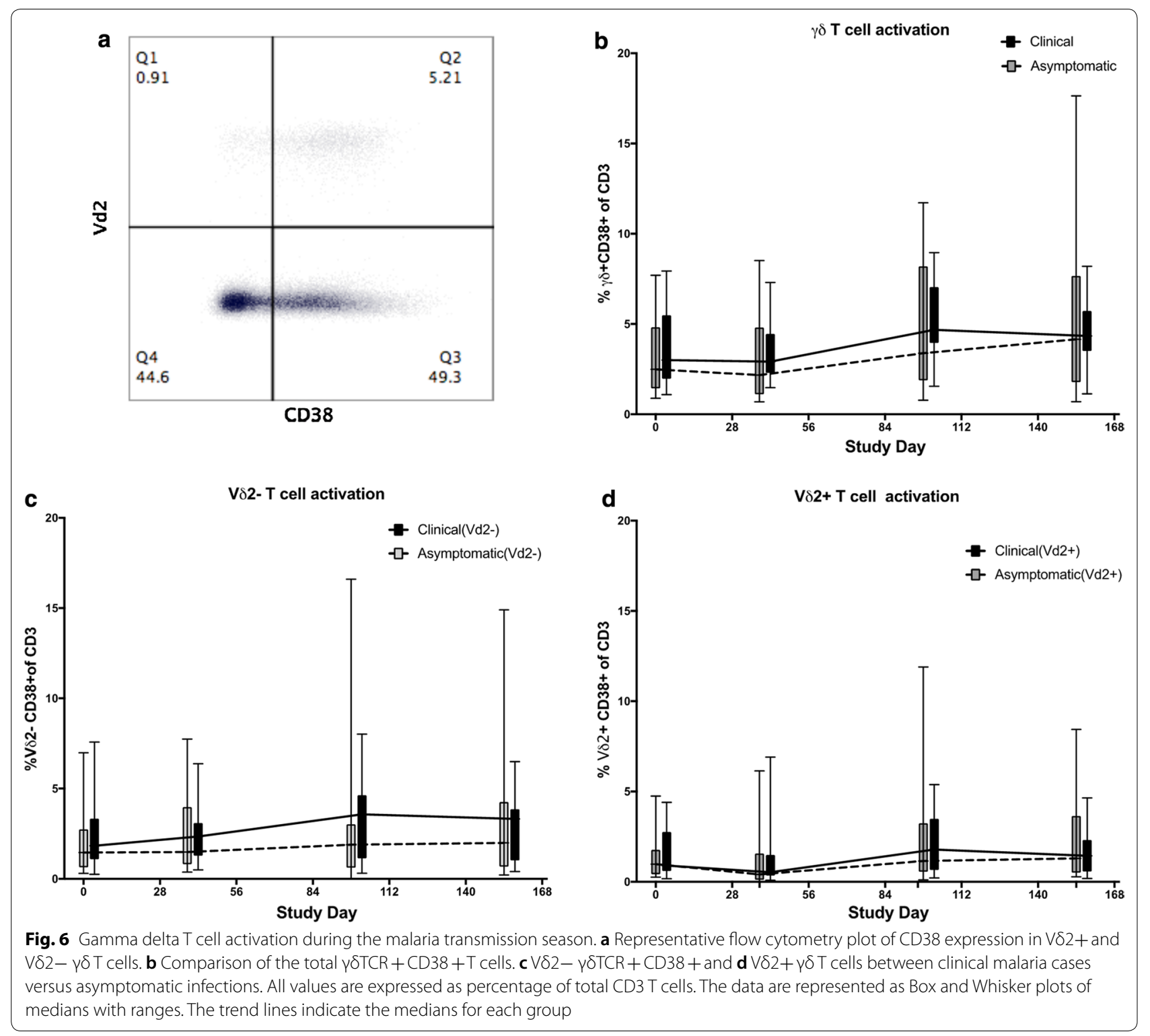

activation of either $\gamma \delta \mathrm{T}$ cell subsets discriminated study participants that had asymptomatic infections from those that had clinical malaria cases.

\section{Abbreviations}

FMPOS: Faculté de Médecine de Pharmacie et d'OdontoStomatologie; IRB: Institutional Review Board: MRTC: Malaria Research Training Center; NIAID: National Institute of Allergy and Infectious Diseases; RPKM: Reads Per Kilobase of transcript per Million mapped reads; USTTB: University of Sciences, Techniques and Technologies of Bamako.

\section{Authors' contributions}

AK, MSS, SAH, OKD, and PED supervised the clinical trial. HD and IZ performed the flow cytometry assays. JK performed statistical analyses. IZ drafted the manuscript which was revised by PED. All authors read and approved the final manuscript.

\section{Author details}

${ }^{1}$ Malaria Research Training Center, International Center of Excellence in Research, Faculty of Medicine and Pharmacy of the University of Sciences, Techniques and Technologies of Bamako, Bamako, Mali. ${ }^{2}$ Laboratory for Malaria Immunology and Vaccinology, National Institute of Allergy and Infectious Diseases, National Institutes of Health, Rockville, MD, USA.

\section{Acknowledgements}

We acknowledge the support from Richard Sakai, Sharon Wong-Madden and the LMIV teams for logistical support during the study in Mali. We thank J. Patrick Gorres for reviewing the manuscript.

\section{Competing interests}

The authors declare that they have no competing interests.

\section{Availability of data and materials}

The raw data supporting the conclusions of this manuscript will be made available by the authors, without undue reservation, to any qualified researcher. 


\section{Consent for publication \\ Not applicable.}

\section{Ethics approval and consent to participate}

All subjects provided written informed consent before screening. Ethics Committee of Faculté de Médecine de Pharmacie et d'OdontoStomatologie (FMPOS) and the NIAID Institutional Review Board (IRB) approved the study protocol (Number: 14-I-N010).

\section{Funding}

This work was supported by the Division of Intramural Research at the National Institute of Allergy and Infectious Diseases, National Institutes of Health.

\section{Publisher's Note}

Springer Nature remains neutral with regard to jurisdictional claims in published maps and institutional affiliations.

Received: 22 January 2019 Accepted: 1 March 2019

Published online: 12 March 2019

\section{References}

1. WHO. World Malaria Report. Geneva: World Health Organization; 2016.

2. Doolan DL, Dobano C, Baird JK. Acquired immunity to malaria. Clin Microbiol Rev. 2009;22:13-36.

3. Tran TM, Ongoiba A, Coursen J, Crosnier C, Diouf A, Huang CY, et al. Naturally acquired antibodies specific for Plasmodium falciparum reticulocytebinding protein homologue 5 inhibit parasite growth and predict protection from malaria. J Infect Dis. 2014;209:789-98.

4. Langhorne J, Ndungu FM, Sponaas AM, Marsh K. Immunity to malaria: more questions than answers. Nat Immunol. 2008:9:725-32.

5. Finney OC, Nwakanma D, Conway DJ, Walther M, Riley EM. Homeostatic regulation of $T$ effector to Treg ratios in an area of seasonal malaria transmission. Eur J Immunol. 2009;39:1288-300.

6. Portugal S, Moebius J, Skinner J, Doumbo S, Doumtabe D, Kone Y, et al. Exposure-dependent control of malaria-induced inflammation in children. PLoS Pathog. 2014;10:e1004079.

7. Walther M, Jeffries D, Finney OC, Njie M, Ebonyi A, Deininger S, et al. Distinct roles for FOXP3 and FOXP3 CD4 T cells in regulating cellular immunity to uncomplicated and severe Plasmodium falciparum malaria. PLoS Pathog. 2009;5:e1000364.

8. Jagannathan P, Kim CC, Greenhouse B, Nankya F, Bowen K, Eccles-James I, et al. Loss and dysfunction of Vdelta2(+) gamma delta T cells are associated with clinical tolerance to malaria. Sci Transl Med. 2014;6:251 ra117.

9. Chang WL, van der Heyde H, Maki DG, Malkovsky M, Weidanz WP. Subset heterogeneity among gamma delta T cells found in peripheral blood during Plasmodium falciparum malaria. Immunol Lett. 1992;32:273-4.

10. Bordessoule D, Gaulard P, Mason DY. Preferential localisation of human lymphocytes bearing gamma delta $T$ cell receptors to the red pulp of the spleen. J Clin Pathol. 1990;43:461-4.
11. Perera MK, Carter R, Goonewardene R, Mendis KN. Transient increase in circulating gamma/delta T cells during Plasmodium vivax malarial paroxysms. J Exp Med. 1994;179:311-5.

12. Ho M, Tongtawe $P$, Kriangkum J, Wimonwattrawatee T, Pattanapanyasat $K$, Bryant $L$, et al. Polyclonal expansion of peripheral gamma delta T cells in human Plasmodium falciparum malaria. Infect Immun. 1994:62:855-62.

13. Ho M, Webster HK, Tongtawe P, Pattanapanyasat K, Weidanz WP. Increased gamma delta T cells in acute Plasmodium falciparum malaria. Immunol Lett. 1990;25:139-41.

14. Hayday AC. Gamma delta cells: a right time and a right place for a conserved third way of protection. Annu Rev Immunol. 2000;18:975-1026.

15. Casorati G, De Libero G, Lanzavecchia A, Migone N. Molecular analysis of human gamma/delta + clones from thymus and peripheral blood. J Exp Med. 1989;170:1521-35.

16. Davey MS, Willcox CR, Joyce SP, Ladell K, Kasatskaya SA, McLaren JE, et al. Clonal selection in the human Vdelta1 $T$ cell repertoire indicates gamma delta TCR-dependent adaptive immune surveillance. Nat Commun. 2017:8:14760

17. Sissoko MS, Healy SA, Katile A, Omaswa F, Zaidi I, Gabriel EE, et al. Safety and efficacy of PfSPZ vaccine against Plasmodium falciparum via direct venous inoculation in healthy malaria-exposed adults in Mali: a randomised, double-blind phase 1 trial. Lancet Infect Dis. 2017;17:498-509.

18. Zaidi I, Diallo H, Conteh S, Robbins Y, Kolasny J, Orr-Gonzalez S, et al. Gamma delta $T$ cells are required for the induction of sterile immunity during irradiated sporozoite vaccinations. J Immunol. 2017:199:3781-8.

19. de Jong SE, Asscher VER, Wammes LJ, Wiria AE, Hamid F, Sartono E, et al. Longitudinal study of changes in gammadelta T cells and CD4(+) T cells upon asymptomatic malaria infection in Indonesian children. Sci Rep. 2017:7:8844.

20. Hviid L, Kurtzhals JA, Adabayeri V, Loizon S, Kemp K, Goka BQ, et al. Perturbation and proinflammatory type activation of $\mathrm{V}$ delta $1(+)$ gamma delta T cells in African children with Plasmodium falciparum malaria. Infect Immun. 2001;69:3190-6.

21. Taniguchi T, Md Mannoor K, Nonaka D, Toma H, Li C, Narita M, et al. A unique subset of gammadelta $T$ cells expands and produces $\mathrm{IL}-10$ in patients with naturally acquired immunity against falciparum malaria. Front Microbiol. 2017;8:1288.

22. Guenot M, Loizon S, Howard J, Costa G, Baker DA, Mohabeer SY, et al. Phosphoantigen burst upon Plasmodium falciparum schizont rupture can distantly activate Vgamma9Vdelta2 T cells. Infect Immun. 2015;83:3816-24

23. Jagannathan $P$, Lutwama F, Boyle MJ, Nankya F, Farrington LA, Mclntyre $\mathrm{Tl}$, et al. Vdelta2 + T cell response to malaria correlates with protection from infection but is attenuated with repeated exposure. Sci Rep. 2017;7:11487.

24. Schofield L, loannidis LJ, Karl S, Robinson LJ, Tan QY, Poole DP, et al. Synergistic effect of $\mathrm{IL}-12$ and $\mathrm{IL}-18$ induces TIM3 regulation of gammadelta T cell function and decreases the risk of clinical malaria in children living in Papua New Guinea. BMC Med. 2017;15:114.

Ready to submit your research? Choose BMC and benefit from

- fast, convenient online submission

- thorough peer review by experienced researchers in your field

- rapid publication on acceptance

- support for research data, including large and complex data types

- gold Open Access which fosters wider collaboration and increased citations

- maximum visibility for your research: over 100M website views per year

At BMC, research is always in progress.

Learn more biomedcentral.com/submissions 